\title{
Oriented growth of porphyrin-based molecular wires on ionic crystals analysed by nc-AFM
}

\author{
Thilo Glatzel ${ }^{* 1}$, Lars Zimmerli ${ }^{1}$, Shigeki Kawai ${ }^{1}$, Ernst Meyer ${ }^{1}$, \\ Leslie-Anne Fendt ${ }^{2}$ and Francois Diederich ${ }^{2}$
}

\section{Full Research Paper}

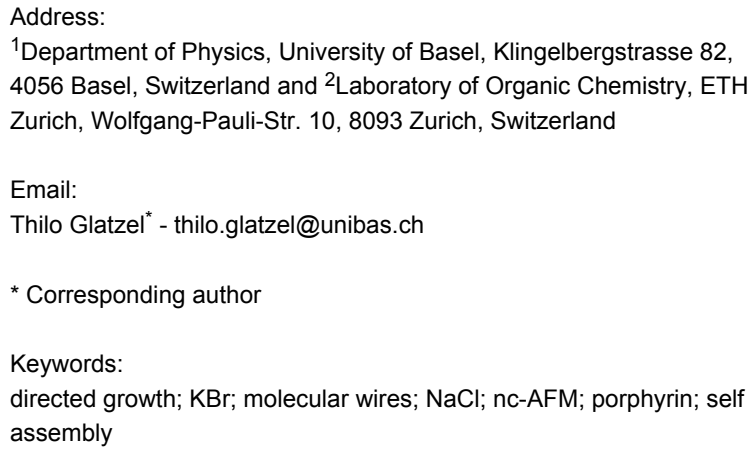

${ }^{1}$ Department of Physics, University of Basel, Klingelbergstrasse 82, 4056 Basel, Switzerland and ${ }^{2}$ Laboratory of Organic Chemistry, ETH Zurich, Wolfgang-Pauli-Str. 10, 8093 Zurich, Switzerland

Email:

Thilo Glatzel* - thilo.glatzel@unibas.ch

* Corresponding author

Keywords:

directed growth; $\mathrm{KBr}$; molecular wires; $\mathrm{NaCl}$; nc-AFM; porphyrin; self assembly

Open Access

Beilstein J. Nanotechnol. 2011, 2, 34-39.

doi:10.3762/bjnano. 2.4

Received: 18 November 2010

Accepted: 22 December 2010

Published: 13 January 2011

This article is part of the Thematic Series "Scanning probe microscopy and related methods".

Guest Editor: E. Meyer

(C) 2011 Glatzel et al; licensee Beilstein-Institut.

License and terms: see end of document.

\begin{abstract}
The growth of molecular assemblies at room temperature on insulating surfaces is one of the main goals in the field of molecular electronics. Recently, the directed growth of porphyrin-based molecular wires on $\operatorname{KBr}(001)$ was presented. The molecule-surface interaction associated with a strong dipole moment of the molecules was sufficient to bind them to the surface; while a stabilization of the molecular assemblies was reached due to the intermolecular interaction by $\pi-\pi$ binding. Here, we show that the atomic structure of the substrate can control the direction of the wires and consequently, complex molecular assemblies can be formed. The electronic decoupling of the molecules by one or two monolayers of $\mathrm{KBr}$ from the $\mathrm{Cu}(111)$ substrate is found to be insufficient to enable comparable growth conditions to bulk ionic materials.
\end{abstract}

\section{Introduction}

One of the main challenges of artificial photosynthesis and molecular electronics is the controlled growth of molecules on the nanometer scale in a certain direction. For the construction of electronic devices, nanowires are essential components which provide an efficient transport of electrons and/or excitons along specific directions. Compared to semiconductor based devices, self-assembled molecules provide some distinct advantages such as self-healing [1] and a decreased number of defects [2-4]. For some time, studies on molecular growth were limited to metal substrates analyzed by scanning tunneling microscopy (STM) (for a few selected examples see [5-13]). Alkali halide thin insulating films on metal surfaces are often regarded as the model system for both testing experimental methodologies and validating new theories. In particular $\mathrm{NaCl}$ thin films have already proved their importance as homogeneous ultrathin spacer layers to separate single molecules from the metal substrate [14-16]. Nevertheless, complete electrical decoupling of such devices from the substrate requires bulk insulators or thick 
insulating films. Several studies by non-contact atomic force microscopy (nc-AFM) were done on ionic crystals with adsorbed PTCDA [17-22], PTCDI [23] or $\mathrm{C}_{60}$ [24]. In the case of porphyrins, the growth [25-27] and electronic properties [28] of stable, monolayered molecular wires on $\operatorname{KBr}(001)$ with a length of up to several hundred nanometers have been observed at room temperature (rt). Even the contacting of self-ordering molecular wires by nanolithography was shown recently [29].

Controlled growth procedures of molecules on insulators are often hindered by the weak, unspecific interaction between the molecules and the insulating surfaces which leads to diffusion on the surfaces and assembly of disordered aggregates. One possibility to overcome this barrier is the use of a specific end group which induces an adequate directed dipole moment within the molecule [26,30]. Moreover, high resolution measurements of molecules on insulating surfaces were scarce due to a lack of suitable imaging techniques. However, recent progress in high resolution nc-AFM has given the opportunity to verify the proposed concept of directed growth of molecular wires on insulators [31-33]. Alkali halides offer some distinct advantages compared to other surfaces. Flat surfaces with monoatomic steps and large terraces are easily prepared and electron bombardment leads to well-structured surfaces [34]. Additionally, these materials have rather large unit cells which allow to obtain atomic resolution fairly easily $[35,36]$.

In the work presented here we focus on the influence of the substrate on the growth process of meso-(4-cyanophenyl)-substituted $\mathrm{Zn}(\mathrm{II})$ porphyrin molecular wires self-assembled on $\mathrm{KBr}(001)$ and $\mathrm{NaCl}(001)$ studied by nc-AFM. We found that the lattice spacing of the ionic crystal has a direct impact on the growth direction of the wires. Extending the studies, the selfassemblies of molecules onto thin ionic films deposited on $\mathrm{Cu}(111)$ revealed that the growth process is also strongly influenced by the metal substrate even for several monolayer of $\mathrm{KBr}$ which also indicates an imperfect electronic decoupling.

\section{Results and Discussion}

Cleaving $\mathrm{KBr}$ crystals in vacuum and annealing them at moderate temperatures results in the formation of wide terraces with step edges in [100] direction which can be as long as several hundred nanometers. Evaporating the cyano-porphyrins onto the bulk $\mathrm{KBr}(001)$ surface results, as also reported earlier $[25,26]$, in the formation of molecular wires. Figure 1 shows a topographic measurement on a $\operatorname{KBr}(001)$ surface, decorated with cyano-porphyrines. The molecular monowires (1) are found to be more than $700 \mathrm{~nm}$ long mainly depending on the length of the step. Along one and two monolayer step edges, single molecular wires are found while at higher steps disordered aggregates of molecules (2) appear. Based on simple geometrical considerations and taking into account the strong dipole moment of the molecules, the special expansion of the aryl side groups and the enhanced electrostatic field at the step edge result in a basic model of the wire formation as presented in Figure 1b, Figure 1c and Figure 1d. Single molecules are highly mobile at rt at the surface. Due to an electrostatic interaction between the dipole moments of the molecules and the enhanced periodic electrostatic field at a step edge compared to the flat surface, the molecules are attracted towards the steps. A stabilization of the wire is enabled due to a $\pi-\pi$ binding between the porphyrin cores of the molecules. Increasing the
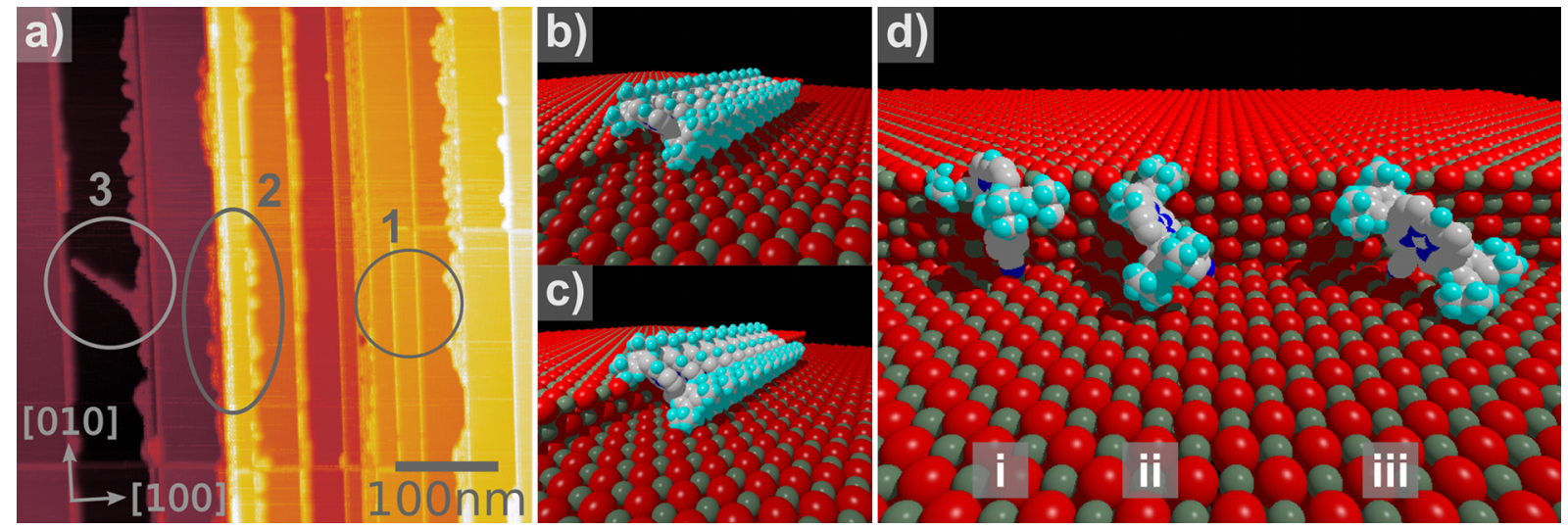

Figure 1: (a) Topographical measurement of molecular structures at $\mathrm{KBr}$ step edges showing monowires (1), unordered agglomerates (2) and multiwires (3). Scan range $=500 \times 500 \mathrm{~nm}^{2}, A_{1 \mathrm{st}}=20 \mathrm{~Hz}, \Delta f_{1 \mathrm{st}}=-8 \mathrm{~Hz}$. The arrangements estimated from height profiles along single and double steps are shown in (b) and (c), respectively. The tilt angle of the molecules has to adopt to fulfil geometrical conditions. Along a triple step, one dimensional wires were never observed. (d) Three different orientations of molecules at those edges. The leftmost molecule (i) in (d) is turned by $45^{\circ}$ so that the core is oriented along the [110] direction. This orientation does not allow $\pi-\pi$ stacking along the direction of the step edges. The molecule in the middle (ii) is tilted by $45^{\circ}$ to the surface, making it fit geometrically to the step. (iii) combines those two angles and could be considered as a possible arrangement for the growth in the [110] direction. 
step height changes the tilt angle of the molecules towards the surface which is inherently coupled with a weaker $\pi-\pi$ interaction and therefore a more fragile molecular wire.

The analysis of our measurements resulted in a wire height of $0.8-0.9 \mathrm{~nm}$ and of $1.2-1.3 \mathrm{~nm}$ for the one and two monolayer (1ML and $2 \mathrm{ML}$ ) step edges, respectively. Assuming that the height of a single molecule from the cyanophenyl to the upper parts of the aryl groups is roughly $1.5 \mathrm{~nm}$ (the calculated height would be $14.989 \AA$ plus the van der Waals radii of one hydrogen and one nitrogen atom) and that the molecules are not laterally tilted, this would lead to a tilt angle of roughly $57 \pm 5^{\circ}$ for the $2 \mathrm{ML}$ and $35 \pm 5^{\circ}$ for the $1 \mathrm{ML}$ step edge with respect to the substrate. Balaban et al. [37] showed that the distance between two molecules in the $\pi-\pi$ plane is approximately $3.6 \AA$, which leads to a distance of $5.9 \AA$ parallel to the surface for a tilt angle of $37^{\circ}$ between the porphyrin core and the $\pi-\pi$ direction. This angle is observed in crystallographic assemblies of those molecules as well as in former nc-AFM studies $[25,26]$. Taking also into account a vertical tilt angle, determined by the aryl groups (Figure 1b and Figure 1c), the measured height of the molecules results in a tilt angle in the $\pi-\pi$ stack direction of $37^{\circ}$ and $43^{\circ}$ for the $1 \mathrm{ML}$ and the $2 \mathrm{ML}$ step, respectively. Both values indicate a stable $\pi-\pi$ interaction, while for $3 \mathrm{ML}$ steps and higher no stable configurations can be found for a single molecular wire (see Figure 1d). As already visible in Figure 1a, the unordered agglomerates (3) are the source of multi-wire structures. These structures are parallel ordered single molecular wires growing in the $\langle 110\rangle$ directions on $\mathrm{KBr}$. High-resolution nc-AFM measurements of these structures [26] revealed a separation of the single wires by $2.4 \pm 0.2 \mathrm{~nm}$ which corresponds to approximately five lattice spacings of the substrate. Pšenčík et al. determined distances between different bacteriochlorophyll stacks of 2.1-3.0 nm in natural chromosomes; the same order of magnitude as observed for the porphyrin assemblies [38]. Since the photon capture crosssection might be markedly increased, hence, leading to higher efficiencies with a broader wavelength range compared to silicon solar cells, such antennae systems are for example also of potential interest for hybrid solar cells that could operate under low or moderate light conditions. Furthermore, porphyrins are known to be very promising building blocks: They are not only very stable, inexpensive and quickly accessible, but also both the periphery and the central metal are very easy to modify. Therefore, such porphyrin wires can be tuned with a high degree of freedom.

FFT-analysis of measurements [26] showing simultaneous molecular and atomic resolution of the substrate revealed that, unlike at step edges in [100] direction, the molecule-to-molecule distance within a wire differs from the $\mathrm{KBr}$ lattice spacing. The molecule-molecule separation measures 5.6 $\AA$, compared to the distance of $4.6 \AA$ between two $\mathrm{K}^{+}$ions along the $\langle 110\rangle$ directions. This indicates that the dimensions of the molecule ask for a larger separation than the $\mathrm{K}^{+}$ions intervals could provide, rather corresponding to the spacings observed in the crystal lattice of Balaban et al. [37]. At the steps along the [100] direction, $\mathrm{K}^{+}$ions are alternating with $\mathrm{Br}^{-}$ions creating attractive and repulsive sites for the partially negative charged cyanogroups and therefore forcing them into position. Diagonally across the lattice in $\langle 110\rangle$ directions, the $\mathrm{K}^{+}$ions are evidently closer together and not interrupted by bromine ions, presumably creating a slightly delocalized positive charge distribution. The stacks are directed along one dimension but in contrast to the assemblies at the step edges, the single porphyrins are not located each directly above a potassium ion, but rather along the $\mathrm{K}^{+}$chain, keeping their thermodynamically preferred intermolecular spacing. The molecular wires are most likely inclined to the surface, with the cyano-groups pointing downwards and the big side groups standing out more on one side (Figure 2b). Heights between 1.5-2.0 nm were measured for multi-wires, depending on the tilt angle of the stacks respective to the surface.

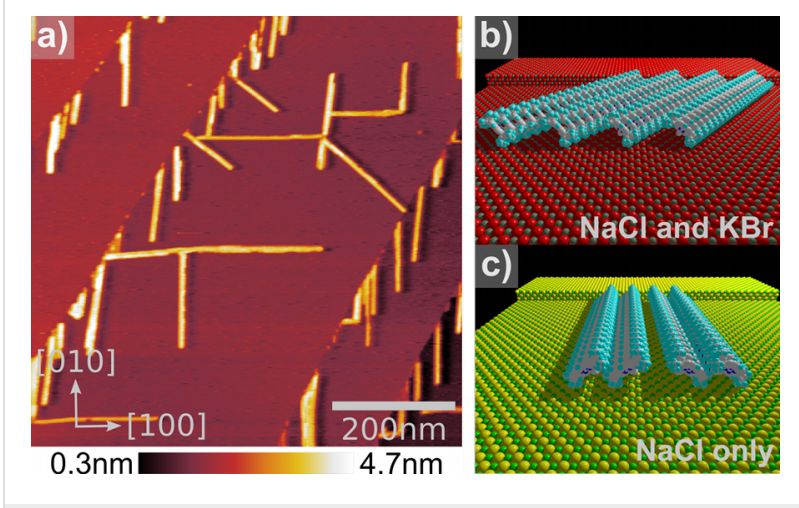

Figure 2: (a) Topography of cyano-porphyrin molecular wires on a $\mathrm{NaCl}$ single crystal surface. In contrast to the growth on $\mathrm{KBr}$, the molecular wires are also oriented along the [100] direction of the substrate. In (b) and (c) the two different growth directions are schematically visualized.

Looking at the spacing of $5.6 \AA$ between the stacked molecules leads to the assumption that $\mathrm{NaCl}$ with a lattice constant of $5.65 \AA$ is an ideal substrate to grow multi-wires on. $\mathrm{NaCl}$ is chemically and physically similar to $\mathrm{KBr}$ and is therefore a good sample to investigate the influence of the lattice distance of the substrate to the self-assemblies. Figure 2a shows an overview nc-AFM image of the molecular assemblies on $\mathrm{NaCl}(001)$. The step edges have no specific direction and show no ordered molecular decorations. Regions with steps in $\langle 100\rangle$ directions show similar single-wire decoration as the $\operatorname{KBr}(001)$ surface did. Additionally, we observe a large amount of broader structures growing across the terraces which presumably start 
growing from kink sites at the step edges. The main difference which was observed between self-assembly on $\mathrm{KBr}$ and $\mathrm{NaCl}$ is the tendency of the molecules to form crossing carpets or networks of wires. Figure 2a shows such a network of several wire-junctions. The angles between the structures are not only $90^{\circ}$ as observed on $\mathrm{KBr}$ but also $45^{\circ}$ indicating a growth oriented in all major crystallographic surface directions. The structures along the $\langle 100\rangle$ directions do not differ in shape or thickness from the ones oriented in the $\langle 110\rangle$ directions. The molecules along the $\langle 100\rangle$ directions on $\mathrm{NaCl}$ are most certainly adsorbed at every sodium atom. That leads to an intermolecular distance of $5.65 \AA$ making wire growth along this direction more favorable compared to $\mathrm{KBr}$. However, wires along the $\langle 110\rangle$ directions can still grow from kink sites or wire junctions. In Figure $2 b$ and Figure $2 c$ structural models for $\operatorname{KBr}(001)$ and $\mathrm{NaCl}(001)$ are presented.

To study the influence of a metal substrate on the formation of the molecular wires and assemblies, we evaporated the cyanoporphyrin molecules onto thin $\mathrm{KBr}$ films grown on $\mathrm{Cu}(111)$. In Figure 3, a series of topographical images can be seen. In (a) a $100 \times 100 \mathrm{~nm}^{2}$ overview of ordered cyano-porphyrin assemblies on single and double $\mathrm{KBr}$ layers is shown. $\mathrm{KBr}$ steps in $\langle 100\rangle$ directions of the second ML are decorated by not only one single molecular wire as observed on the bulk material but with a multi-wire. Furthermore, $\mathrm{Cu}$ steps indicated by small arrows from the left to the right side of the image overgrown by $\mathrm{KBr}$ are also partially decorated by the molecules. Additionally, an assembly is originated from the underlying $\mathrm{Cu}$ step and grows towards the lower image edge. It is then interrupted by a conventional wire along a $\mathrm{KBr}$ island. Figure $3 \mathrm{~b}$ and Figure $3 \mathrm{c}$ show a $30 \times 30 \mathrm{~nm}^{2}$ topography image of the assembly, already revealing submolecular details as well as atomic resolution of the underlying $\mathrm{KBr}$. First, the molecular assembly is not aligned along a certain substrate direction of the $\mathrm{KBr}$ layer. The rows are inclined by $\approx 10^{\circ}$ to the [010] direction of the $\mathrm{KBr}$ layer. Second, submolecular contrast does not reveal a wire like configuration as observed for the multi-wires on bulk ionic crystals. The molecules lay rather flat on the surface since the whole structure is only $0.9-1.0 \mathrm{~nm}$ in height.

These measurements also reveal the relatively weak binding energy of the molecules to the substrate: Already during the change of the set point, parts of the layer on the left lower side were removed while scanning from bottom to top. The first few lines of Figure $3 \mathrm{c}$ were scanned with an increased frequency shift of $\Delta f_{1 \mathrm{st}}=-11 \mathrm{~Hz}$. After the removal of the first molecules, the set point was lowered to $\Delta f_{1 \mathrm{st}}=-10 \mathrm{~Hz}$ again. Regardless of that, the tip continued to remove molecules thinning the structure to $50 \%$ of its original size. It is remarkable that even though the tip is removing molecules the scan remained absolutely stable and maintained a high resolution ability during all the performed manipulations. The amount of removed molecules and the shape of the resulting structure suggest that the molecules are arranged in a superstructure of about $6-8 \mathrm{~nm}$ width. Both columns visible in Figure $3 b$ and Figure $3 c$ show periodic and distinct features proving that they are real submolecular features. Nevertheless, suggesting an appropriate model of the molecular arrangement based only on these measurements has proven to be difficult. However, it can be concluded that the influence of the $\mathrm{Cu}(111)$ substrate on the molecular assemblies and wires hinders the formation of mono-and multiwire cyano-porphyrin assemblies stabilized by an intermolecular $\pi-\pi$ interaction.

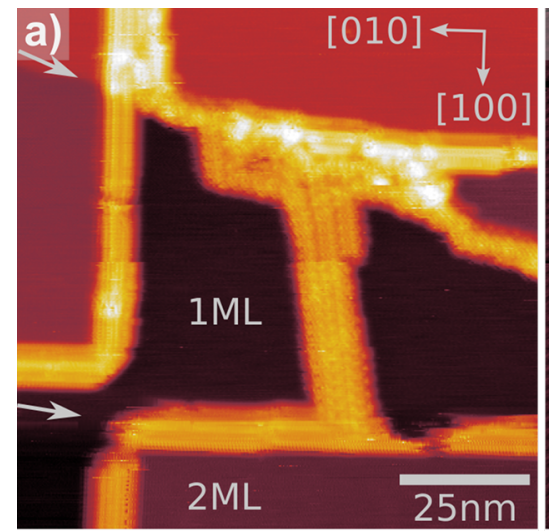

Onm

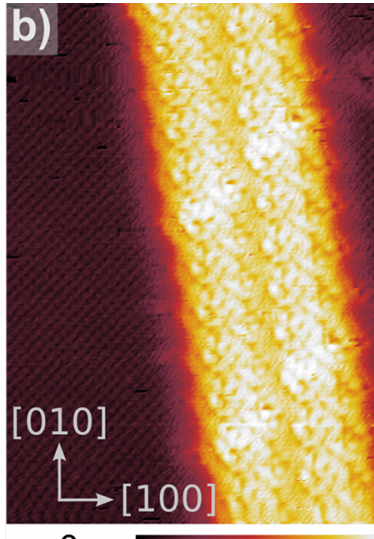

Onm

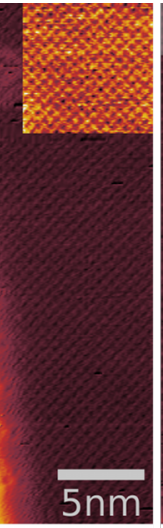

$1.3 \mathrm{~nm}$

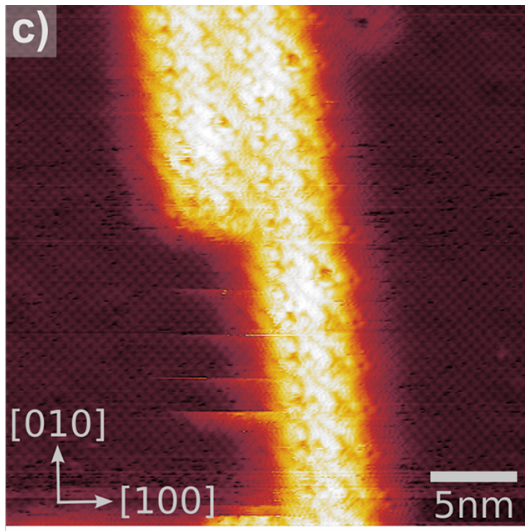

Onm

Figure 3: nc-AFM measurements of molecular assemblies grown on an ultrathin $\mathrm{KBr}$ layer on $\mathrm{Cu}(111)$. (a) $100 \times 100 \mathrm{~nm}^{2}$ overview of ordered cyanoporphyrin assemblies on single and double $\mathrm{KBr}$ layers. (b) and (c) $30 \times 30 \mathrm{~nm}^{2} \mathrm{zoom}$ in of the free standing molecular assembly on a single $\mathrm{KBr}$ layer. Clear sub-molecular resolution as well as atomic resolution is observed. After decreasing the set-point, parts of the assembly are removed and the atomic corrugation below becomes visible. 


\section{Conclusion}

The adsorption of cyano-porphyrin molecules was studied for bulk $\mathrm{KBr}$ and $\mathrm{NaCl}$ samples and resulted in various reproducible assemblies on the surfaces. Especially step edges and kinks of the alkali halide crystals act as trapping points for the polar molecules, preventing them from diffusing freely over the surface. Simultaneously, intermolecular interactions force the cyano-porphyrins to form $\pi-\pi$ stacks. These wires grow along the edges, forming long one-dimensional molecular structures. The growth is affected by the potential corrugation at the step edge which forces the negatively charged nitrogen atom of the cyano-porphyrin to sit on top of a positively charged ion. This results in an intermolecular distance corresponding to the lattice constant of the underlying substrate. At increased molecule coverages, two-dimensional arrays start to grow away from the steps across the terraces. The preferred growth orientation is the (110) direction on $\mathrm{KBr}$ while on $\mathrm{NaCl}$ also assemblies oriented in (100) direction are found. The different growth mode is directed by the lattice spacing of the underlying substrate and the equilibrium distance of the $\pi-\pi$ interaction of the molecules. The absorption behavior of the cyano-porphyrins was also studied on ultrathin $\mathrm{KBr}$ films on $\mathrm{Cu}(111)$. We have shown that $\mathrm{KBr}$ thin films can be used as a substrate for the molecular assemblies at room temperature. Nevertheless, the first layers of $\mathrm{KBr}$ are still not sufficient to decouple the molecules completely from the underlying $\mathrm{Cu}$ substrate. On areas close to an underlying copper step, porphyrins grow in a hexagonal lattice structure and are probably adsorbed with their core more parallel to the surface loosing their intermolecular $\pi-\pi$ stacking.

\section{Experimental}

Experiments were performed under ultrahigh vacuum (UHV) conditions with a base pressure below $10^{-10}$ mbar using a home built non-contact atomic force microscope operated at rt [39]. In the nc-AFM mode, the tip-sample distance is usually controlled by maintaining a constant shift of the first flexural resonance frequency $f_{1 \text { st }}$ with respect to the resonance far from the surface. Highly doped silicon cantilevers with integrated tips (Nanosensors, NCL), a typical resonance frequency $f_{1 \mathrm{st}} \approx 160 \mathrm{kHz}$ and a spring constant $k \approx 30 \mathrm{~N} / \mathrm{m}$ were employed as a force sensor. The typical oscillation amplitude measures about $A_{1 \mathrm{st}} \approx$ 5-20 $\mathrm{nm}$. The cantilevers were annealed in UHV (30 min at $\left.120^{\circ} \mathrm{C}\right)$ and sputtered $(1-2 \mathrm{~min}$ at $680 \mathrm{eV})$ with $\mathrm{Ar}^{+}$ions for cleaning. In the experiments reported here, meso-(4cyanophenyl)-substituted $\mathrm{Zn}$ (II) porphyrin (cyano-porphyrin, Figure 4) was thermally evaporated from a Knudsen cell at $160{ }^{\circ} \mathrm{C}$ (with a rate of the order of $10 \AA / \mathrm{min}$ ) onto bulk crystals of $\mathrm{NaCl}$ and $\mathrm{KBr}$ as well as on ultrathin $\mathrm{KBr}$ layers on a $\mathrm{Cu}(111)$ substrate. During evaporation the samples were held at $80{ }^{\circ} \mathrm{C}$ to enhance the diffusion of the molecules at the surface. The synthesis of the cyano-porphyrin molecules has been described in detail in [40]. The bulk crystals were cleaved in UHV followed by an annealing step at $150{ }^{\circ} \mathrm{C}$ to reduce surface charges. In our experiments we used additionally a $\mathrm{Cu}(111)$ surface which was prepared in UHV according to regular surface science techniques by several cycles of $\mathrm{Ar}^{+}$ion bombardment and subsequent annealing to $520{ }^{\circ} \mathrm{C}$. $\mathrm{KBr}$ thin films were deposited on the clean $\mathrm{Cu}(111)$ substrates by sublimation, using a temperature controlled Knudsen cell. As a source material, crushed salt powder obtained from alkali halide single crystals was used. In order to obtain thin layers of $\mathrm{KBr}$, choosing a very low evaporation rate of $\approx 0.2 \AA / \mathrm{min}$ proved to be successful.

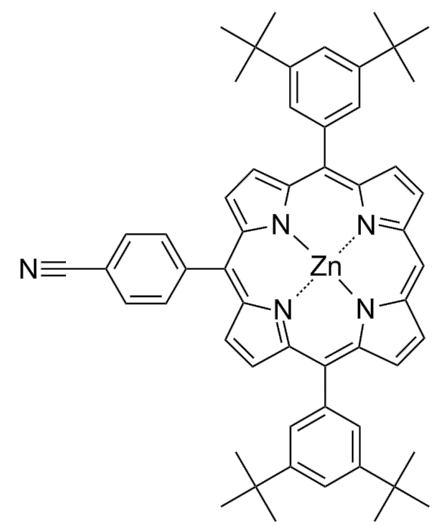

Figure 4: Chemical structure of the meso-(4-cyanophenyl)-substituted $\mathrm{Zn}$ (II) porphyrin investigated in this study [40]. The dipole moment of the molecule along the $\mathrm{C}-\mathrm{N}$ bond is $4.37 \mathrm{D}$.

\section{Acknowledgements}

This work was supported by the Swiss National Science Foundation (SNF), the Swiss National Center of Competence in Research on Nanoscale Science (NCCR-Nano) and the European Project IST-FET Pico-Inside.

\section{References}

1. Kawai, S.; Maier, S.; Glatzel, T.; Koch, S.; Such, B.; Zimmerli, L.; Fendt, L.-A.; Diederich, F.; Meyer, E. Appl. Phys. Lett. 2009, 95, 103109. doi:10.1063/1.3216057

2. Kay, E. R.; Leigh, D. A.; Zerbetto, F. Angew. Chem., Int. Ed. 2007, 46, 72-191. doi:10.1002/anie.200504313

3. Douglas, P. Supramolecular chemistry: Concepts and perspectives; VCH: Weinheim, Germany, 1996.

4. Whitesides, G. M.; Mathias, J. P.; Seto, C. T. Science 1991, 254, 1312-1319. doi:10.1126/science.1962191

5. Jung, T. A.; Schlittler, R. R.; Gimzewski, J. K. Nature 1997, 386, 696-698. doi:10.1038/386696a0

6. Bonifazi, D.; Spillmann, H.; Kiebele, A.; de Wild, M.; Seiler, P.; Cheng, F.; Güntherodt, H. J.; Jung, T.; Diederich, F. Angew. Chem., Int. Ed. 2004, 43, 4759-4763. doi:10.1002/anie.200460562 
7. Schreiber, F. Prog. Surf. Sci. 2000, 65, 151-257. doi:10.1016/S0079-6816(00)00024-1

8. De Feyter, S.; De Schryver, F. C. Chem. Soc. Rev. 2003, 32, 139-150. doi:10.1039/b206566p

9. Rosei, F.; Schunack, M.; Naitoh, Y.; Jiang, P.; Gourdon, A.; Laegsgaard, E.; Stensgaard, I.; Joachim, C.; Besenbacher, F. Prog. Surf. Sci. 2003, 71, 95-146. doi:10.1016/S0079-6816(03)00004-2

10. Tanaka, S.; Suzuki, H.; Inada, M.; Kamikado, T.; Mashiko, S. Nanotechnology 2005, 16, S107-S111. doi:10.1088/0957-4484/16/3/020

11. Tanaka, S.; Suzuki, H.; Kamikado, T.; Mashiko, S. Thin Solid Films 2003, 438-439, 56-60. doi:10.1016/S0040-6090(03)00758-2

12. Yokoyama, T.; Yokoyama, S.; Kamikado, T.; Okuno, Y.; Mashiko, S. Nature 2001, 413, 619-621. doi:10.1038/35098059

13. Spillmann, H.; Kiebele, A.; Stöhr, M.; Jung, T. A.; Bonifazi, D.; Cheng, F.; Diederich, F. Adv. Mater. 2006, 18, 275-279. doi:10.1002/adma.200501734

14. Repp, J.; Meyer, G.; Paavilainen, S.; Olsson, F. E.; Persson, M. Science 2006, 312, 1196-1199. doi:10.1126/science.1126073

15. Gross, L.; Mohn, F.; Liljeroth, P.; Repp, J.; Giessibl, F. J.; Meyer, G. Science 2009, 324, 1428-1431. doi:10.1126/science.1172273

16. Meyer, E.; Glatzel, T. Science 2009, 324, 1397-1398. doi:10.1126/science.1175869

17. Nony, L.; Bennewitz, R.; Pfeiffer, O.; Gnecco, E.; Baratoff, A.; Meyer, E.; Eguchi, T.; Gourdon, A.; Joachim, C. Nanotechnology 2004, 15, S91-S96. doi:10.1088/0957-4484/15/2/019

18. Kunstmann, T.; Schlarb, A.; Fendrich, M.; Wagner, T.; Möller, R.; Hoffmann, R. Phys. Rev. B 2005, 71, 121403. doi:10.1103/PhysRevB.71.121403

19. Fendrich, M.; Kunstmann, T.; Paulkowski, D.; Möller, R. Nanotechnology 2007, 18, 084004. doi:10.1088/0957-4484/18/8/084004

20. Burke, S. A.; Ji, W.; Mativetsky, J. M.; Topple, J. M.; Fostner, S.; Gao, H. J.; Guo, H.; Grütter, P. Phys. Rev. Lett. 2008, 100, 186104. doi:10.1103/PhysRevLett.100.186104

21. Mativetsky, J. M.; Burke, S. A.; Fostner, S.; Grütter, P. Nanotechnology 2007, 18, 105303. doi:10.1088/0957-4484/18/10/105303

22. Mativetsky, J. M.; Burke, S. A.; Fostner, S.; Grütter, P. Small 2007, 3, 818-821. doi:10.1002/smll.200600699

23. Fendrich, M.; Lange, M.; Weiss, C.; Kunstmann, T.; Möller, R. J. Appl. Phys. 2009, 105, 094311. doi:10.1063/1.3122253

24. Burke, S. A.; Mativetsky, J. M.; Fostner, S.; Grütter, P. Phys. Rev. B 2007, 76, 035419. doi:10.1103/PhysRevB.76.035419

25. Zimmerli, L.; Maier, S.; Glatzel, T.; Gnecco, E.; Pfeiffer, O.; Diederich, F.; Fendt, L.; Meyer, E. J. Phys.: Conf. Ser. 2007, 61, 1357-1360. doi:10.1088/1742-6596/61/1/268

26. Maier, S.; Fendt, L.-A.; Zimmerli, L.; Glatzel, T.; Pfeiffer, O.; Diederich, F.; Meyer, E. Small 2008, 4, 1115-1118. doi:10.1002/smll.200701259

27. Glatzel, T.; Zimmerli, L.; Meyer, E. Isr. J. Chem. 2008, 48, 107-116.

28. Glatzel, T.; Zimmerli, L.; Koch, S.; Kawai, S.; Meyer, E. Appl. Phys. Lett. 2009, 94, 063303. doi:10.1063/1.3080614

29. Gross, L.; Schlittler, R. R.; Meyer, G.; Fendt, L.-A.; Diederich, F.; Glatzel, T.; Kawai, S.; Koch, S.; Meyer, E.

J. Vac. Sci. Technol., B: Microelectron. Nanometer Struct.-Process., M eas., Phenom. 2010, 28, C4D34-C4D39. doi:10.1116/1.3292601

30. Schütte, J.; Bechstein, R.; Rohlng, M.; Reichling, M.; Kühnle, A. Phys. Rev. B 2009, 80, 205421. doi:10.1103/PhysRevB.80.205421
31. Nony, L.; Gnecco, E.; Baratoff, A.; Alkauskas, A.; Bennewitz, R.; Pfeiffer, O.; Maier, S.; Wetzel, A.; Meyer, E.; Gerber, C. Nano Lett. 2004, 4, 2185-2189. doi:10.1021/nl048693v

32. Such, B.; Trevethan, T.; Glatzel, T.; Kawai, S.; Zimmerli, L.; Meyer, E.; Shluger, A. L.; Amijs, C. H. M.; de Mendoza, P.; Echavarren, A. M. ACS Nano 2010, 4, 3429-3439. doi:10.1021/nn100424g

33. Rahe, P.; Nimmrich, M.; Greuling, A.; Schutte, J.; Stara, I. G.; Rybacek, J.; Huerta-Angeles, G.; Stary, I.; Rohlng, M.; Kühnle, A. J. Phys. Chem. C 2010, 114, 1547-1552. doi:10.1021/jp911287p

34. Bennewitz, R.; Schär, S.; Barwich, V.; Pfeiffer, O.; Meyer, E.; Krok, F.; Such, B.; Kolodzej, J.; Szymonski, M. Surf. Sci. 2001, 474, L197-L202. doi:10.1016/S0039-6028(00)01053-0

35. Bammerlin, M.; Lüthi, R.; Meyer, E.; Baratoff, A.; Lü, J.; Guggisberg, M.; Gerber, C.; Howald, L.; Güntherodt, H.-J. Probe Microsc. 1997, 1, 3.

36. Bammerlin, M.; Lüthi, R.; Meyer, E.; Baratoff, A.; Lü, J.; Guggisberg, M.; Loppacher, C.; Gerber, C.; Güntherodt, H.-J. Appl. Phys. A: Mater. Sci. Process. 1998, 66, S293-S294. doi:10.1007/s003390051148

37. Balaban, T. S.; Linke-Schaetzel, M.; Bhise, A. D.; Vanthuyne, N.; Roussel, C.; Anson, C. E.; Buth, G.; Eichhöfer, A.; Foster, K.; Garab, G.; Gliemann, H.; Goddard, R.; Javorfi, T.; Powell, A. K.; Rösner, H.; Schimmel, T. Chem.-Eur. J. 2005, 11, 2267-2275. doi:10.1002/chem.200400664

38. Pšencík, J.; Arellano, J. B.; Ikonen, T. P.; Borrego, C. M.; Laurinmäki, P. A.; Butcher, S. J.; Serimaa, R. E.; Tuma, R. Biophys. J. 2006, 91, 1433-1440. doi:10.1529/biophysj.106.084228

39. Howald, L.; Meyer, E.; Lüthi, R.; Haefke, H.; Overney, R.; Rudin, H.; Güntherodt, H. J. Appl. Phys. Lett. 1993, 68, 117-119. doi:10.1063/1.109732

40. Cheng, F.; Zhang, S.; Adronov, A.; Echegoyen, L.; Diederich, F. Chem.-Eur. J. 2006, 12, 6062-6070. doi:10.1002/chem.200600126

\section{License and Terms}

This is an Open Access article under the terms of the Creative Commons Attribution License (http://creativecommons.org/licenses/by/2.0), which permits unrestricted use, distribution, and reproduction in any medium, provided the original work is properly cited.

The license is subject to the Beilstein Journal of Nanotechnology terms and conditions: (http://www.beilstein-journals.org/bjnano)

The definitive version of this article is the electronic one which can be found at: $\underline{\text { doi: } 10.3762 / \text { bjnano. } 2.4}$ 